\title{
Ação de fosfitos de potássio no manejo de mofo branco em soja
}

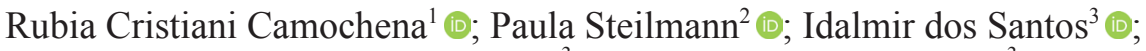

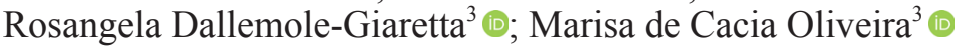

${ }^{1}$ Universidade Tecnológica Federal do Paraná - UTFPR, Rua Luiz Detoni, 334 - Bairro Fraron, CEP: 85500-000, Pato Branco -PR, Brasil. *Trabalho referente a tese de doutorado. ${ }^{2}$ Universidade Tecnológica Federal do Paraná - UTFPR, Rua Ilga Sanzovo, 4788 - Bairro Jardins II, CEP: 85560-000, Chopinzinho -PR, Brasil. ${ }^{3}$ Universidade Tecnológica Federal do Paraná, Via do Conhecimento, Km 1. CEP: $85503-390$ Pato Branco - PR, Brasil. Autor para correspondência: Paula Steilmann (paulasteilmann@gmail.com)

Data de chegada: 05/12/2018. Aceito para publicação em: 19/12/2019.

$10.1590 / 0100-5405 / 217101$

\section{RESUMO}

Camochena, R.C.; Steilmann, P.; Santos, I.; Dallemole-Giaretta, R.; Oliveira, M.C. Ação de fosfitos de potássio no manejo de mofo branco em soja. Summa Phytopathologica, v.46, n.2, p.260-266, 2020.

O mofo branco na cultura da soja é uma doença de difícil controle e o uso de fungicidas não é suficiente para evitar perdas significativas, além de causarem danos ambientais, têm custos elevados. Métodos alternativos, a exemplo dos fertilizantes foliares, a base de fosfito de potássio, também podem ser utilizados no manejo desta doença. Dessa forma, o objetivo do trabalho foi estudar o efeito de fosfitos de potássio no controle do mofo branco na cultura da soja, aplicados em diferentes estádios fenológicos da cultura e a ação destes produtos na indução de respostas de defesa nas plantas. Os fosfitos testados foram: Fosfito A ( $\left.\mathrm{P}_{2} \mathrm{O}_{5}-40 \% ; \mathrm{K}_{2} \mathrm{O}-20 \%\right)$; Fosfito B $\left(\mathrm{P}_{2} \mathrm{O}_{5}-40 \% ; \mathrm{K}_{2} \mathrm{O}-28 \%\right)$; Fosfito $\mathrm{C}\left(\mathrm{P}_{2} \mathrm{O}_{5}-\right.$ $40 \% ; \mathrm{K}_{2} \mathrm{O}-20 \%$ ), Fosfito $\mathrm{D}\left(\mathrm{P}_{2} \mathrm{O}_{5}-30 \% ; \mathrm{K}_{2} \mathrm{O}-20 \%\right)$. O efeito dos fosfitos sobre o patógeno foi avaliado, in vitro, sobre a inibição micelial. Nos testes de indução de resistência foram avaliadas a síntese de gliceolinas, em cotilédones de soja, e as enzimas FAL e POX, avaliadas em plântulas, em câmara de crescimento, pulverizadas com os fosfitos e o fungicida fluazinam. Também foi conduzido um experimento de campo em uma área infestada naturalmente com o fitopatógeno visando avaliar o efeito desses fosfitos no manejo do mofo branco na cultura da soja. Nenhum dos fosfitos testados reduziu o crescimento micelial do patógeno e/ou induziu a síntese de gliceolinas. Por outro lado, todos os fosfitos testados, destacando-se os fosfitos C e D aumentaram a atividade da síntese da FAL e da POX e foram mais efetivos no controle da doença em campo.

Palavras-chave: Sclerotinia sclerotiorum, Manejo alternativo, Indução de resistência

\section{ABSTRACT}

Camochena, R.C.; Steilmann, P.; Santos, I.; Dallemole-Giaretta, R.; Oliveira, M.C. Action of potassium phosphites on the management of white mold in soybean. Summa Phytopathologica, v.46, n.3, p.260-266, 2020.

White mold in the soybean crop is a disease of difficult control and the use of fungicides is not sufficient to prevent significant losses since, besides causing environmental damage, has high costs. Alternative methods, such as foliar fertilizers with potassium phosphite, can also be used in the management of this disease. Therefore, the aim of this study was to evaluate the effect of potassium phosphites on white mold control in soybean through application in different phenological stages of the crop, as well as to assess the action of these products on the induction of defense responses in plants. The tested phosphites were: Phosphite A $\left(\mathrm{P}_{2} \mathrm{O}_{5}-40 \%, \mathrm{~K}_{2} \mathrm{O}-20 \%\right)$; Phosphite B $\left(\mathrm{P}_{2} \mathrm{O}_{5}-40 \%, \mathrm{~K}_{2} \mathrm{O}-28 \%\right)$; Phosphite $\mathrm{C}\left(\mathrm{P}_{2} \mathrm{O}_{5}-40 \%, \mathrm{~K}_{2} \mathrm{O}-20 \%\right)$, and Phosphite $\mathrm{D}\left(\mathrm{P}_{2} \mathrm{O}_{5}-30 \%, \mathrm{~K}_{2} \mathrm{O}-20 \%\right)$. The effect of phosphites on the pathogen was evaluated, in vitro, based on mycelial inhibition. In the resistance induction tests, the synthesis of glyceollins was evaluated in soybean cotyledons and the enzymes PAL and POX were evaluated in seedlings, in a growth chamber, after spraying with the phosphites and the fungicide fluazinam. A field experiment was also carried out in an area naturally infested with the phytopathogen with the aim of evaluating the effect of these phosphites on the management of white mold in the soybean crop. None of the tested phosphites reduced the mycelial growth of the pathogen and/or induced the synthesis of glyceollins. However, all tested phosphites, especially phosphites $\mathrm{C}$ and $\mathrm{D}$, increased PAL and POX synthesis activity and were more effective in controlling the disease in the field.

Keywords: Sclerotinia sclerotiorum, alternative management, resistance induction.

O fungo Sclerotinia sclerotiorum (Lib.) de Bary quando em condições adequadas para o seu desenvolvimento causa a doença conhecida como mofo branco, a qual pode ocasionar grandes perdas na produção de várias culturas, dentre elas a cultura da soja (8).

Uma das maiores dificuldades no controle desta doença é a eliminação do patógeno da área, pois este fungo produz estruturas de resistência denominadas de escleródios, que podem permanecer viáveis por longos períodos. Nesse contexto, a utilização de práticas integradas, como o uso de produtos químicos e biológicos, a rotação de culturas e a utilização de plantas de cobertura de solo, tornam-se aliados no combate ao patógeno, pois não existem no mercado cultivares resistentes a esta doença (25).
Diversos estudos também estão sendo realizados visando a indução de resistência das plantas ao fungo $S$. sclerotiorum $(3,2)$. Como possíveis indutores de resistência a doença de plantas já foram testados o cálcio (2), o benzotiadiazol, a quitosana, a fenilalanina, o ácido salicílico (21) e o fosfito de potássio $(1,14)$, entre outros.

O fosfito de potássio é um composto derivado de ácido fosforoso e é considerado um fertilizante. O íon fosfito tem aproximadamente $7 \%$ a mais de fósforo por molécula do que o fosfato (11). Este composto também pode atuar diretamente, inibindo o crescimento micelial e esporulação do patógeno (13).

Neste contexto, o trabalho teve como objetivo estudar o efeito de fosfitos de potássio no controle do mofo branco na cultura soja, 
aplicados em diferentes estádios fenológicos da cultura e a ação destes produtos na indução de respostas de defesa das plantas.

\section{MATERIAL E MÉTODOS}

\section{Obtenção do patógeno}

O fungo S. sclerotiorum foi isolado a partir de escleródios coletados em lavouras, no município de Coronel Domingos Soares no PR, latitude $26^{\circ} 18^{\prime} 00^{\prime \prime} \mathrm{S}$ e longitude $51^{\circ} 59^{\prime} 21^{\prime}$ ' O, e altitude de $1110 \mathrm{~m}$. Os escleródios foram desinfestados com etanol a $70 \%$ por 30 segundos e, posteriormente, em hipoclorito de sódio a $2 \%$ de cloro ativo, por 1 minuto. Após, os escleródios foram enxaguados por três vezes com água destilada esterilizada e deixados sobre papel filtro seco e esterilizado, para retirar o excesso de água. Em seguida foram colocados em placas de Petri contendo meio de cultura batata-sacarose-ágar (BSA), as quais foram mantidas em câmara de crescimento a $24^{\circ} \mathrm{C}$, com 12 horas de fotoperíodo por 7 dias. Os respectivos isolados foram repicados e armazenados até a utilização.

\section{Efeito de fosfitos de potássio sobre o crescimento micelial de S. sclerotiorum, in vitro}

Neste estudo testaram-se os tratamentos: Fosfito A $\left(\mathrm{P}_{2} \mathrm{O}_{5}-40 \%\right.$; $\left.\mathrm{K}_{2} \mathrm{O}-20 \%\right)$; Fosfito B $\left(\mathrm{P}_{2} \mathrm{O}_{5}-40 \%\right.$; $\left.\mathrm{K}_{2} \mathrm{O}-28 \%\right)$; Fosfito $\mathrm{C}\left(\mathrm{P}_{2} \mathrm{O}_{5}-40 \%\right.$; $\mathrm{K}_{2} \mathrm{O}-20 \%$ ), Fosfito $\mathrm{D}\left(\mathrm{P}_{2} \mathrm{O}_{5}-30 \% ; \mathrm{K}_{2} \mathrm{O}-20 \%\right.$ ), os quais foram misturados em $150 \mathrm{~mL}$ de meio de cultivo BSA fundente, conforme a dosagem recomendada pelo fabricante, homogeneizados e vertidos em placas de Petri de $9 \mathrm{~cm}$ de diâmetro. No tratamento controle utilizou-se somente o meio de cultivo. Após, um disco de BSA de $5 \mathrm{~mm}$ de diâmetro, contendo o micélio de S. sclerotiorum, previamente crescido por sete dias em BSA, foi colocado no centro de cada placa. Em seguida, as placas foram armazenadas em câmara de crescimento a $24^{\circ} \mathrm{C}$ com 12 horas de fotoperíodo. Quando o patógeno ocupou totalmente o meio de cultivo em uma das placas de Petri, avaliou-se o diâmetro de colônia fúngica. O experimento foi conduzido no Delineamento Inteiramente Casualizado (DIC), com sete repetições por tratamento e repetido duas vezes.

\section{Síntese de gliceolinas}

Para avaliação da síntese de gliceolinas, sementes de soja da cultivar BMX Ativa foram semeadas em bandejas, contendo substrato comercial Plantmax ${ }^{\circledR}$ autoclavado e mantidas em casa de vegetação, a $24^{\circ} \mathrm{C}$ com fotoperíodo de 12 horas. Após 15 dias coletaram-se os cotilédones delicadamente, selecionando-os em função do tamanho e ausência de danos. Em laboratório estes foram transferidos para um bécker de $250 \mathrm{~mL}$ de capacidade contendo uma solução de hipoclorito de sódio a $0,23 \%$ de cloro ativo, por 10 minutos. Em seguida, os cotilédones foram lavados três vezes em água destilada esterilizada e transferidos para uma bandeja forrada com papel toalha esterilizado para remoção do excesso de água, por aproximadamente 5 minutos. Todo o processo foi realizado em câmara de fluxo laminar. Em seguida foram realizadas marcações de $1 \mathrm{~cm}$ de diâmetro, com um furador, removendo-se as camadas superiores das células, na face adaxial. Posteriormente, foram colocados cinco cotilédones em cada placa de Petri, contendo papel filtro umedecido. Em cada cotilédone (sobre a área demarcada) foram depositados $50 \mu \mathrm{L}$ dos fosfitos A, B, C e D, separadamente. Como controle positivo foi adicionado extrato de leveduras comercial, desidratado (Saf-Instant ${ }^{\circledR}$ ) e como controle negativo água destilada esterilizada. $\mathrm{O}$ extrato de leveduras foi hidratado com $1 \mathrm{~g}$ em $100 \mathrm{~mL}$ de água destilada e autoclavada por 20 minutos. O sobrenadante foi analisado para a determinação da concentração de açúcares solúveis totais, através da metodologia descrita por Dubois et al. (12).

As placas foram colocadas em câmara de crescimento, por 20 horas a $26^{\circ} \mathrm{C}$, no escuro. Após este período, os cotilédones de cada placa que mantiveram as gotas com os respectivos tratamentos foram colocados em um Erlenmeyer. Em seguida, adicionou-se $1 \mathrm{~mL}$ de água destilada esterilizada para cada cotilédone e estes foram agitados por 1 hora. Posteriormente, efetuou-se a filtragem e o filtrado foi analisado para a presença de gliceolinas, em espectrofotômetro (Shimadzu UV-1800) em comprimento de onda de $285 \mathrm{~nm}(4,26)$.

Cada unidade experimental foi constituída de uma placa de Petri. $\mathrm{O}$ experimento foi conduzido em DIC com cinco repetições por tratamento.

\section{Ativação de enzimas envolvidas na defesa vegetal, em casa de vegetação}

Para avaliação da síntese das enzimas peroxidase (POX) e fenilalanina amônia lisase (FAL) foram semeadas sementes de soja da cultivar BMX ATIVA em vasos de volume de $200 \mathrm{~mL}$, contendo substrato comercial Plantmax ${ }^{\circledR}$, previamente autoclavado e mantidos em câmara de crescimento com temperatura de $24^{\circ} \mathrm{C}$ e fotoperíodo de 12 horas. Quando as plantas atingiram o estádio vegetativo V2, estas foram pulverizadas com os tratamentos: Fosfitos A, B, C e D, e o fungicida fluazinam $\left(500 \mathrm{~g} \mathrm{~L}^{-1}\right.$ i.a). As doses dos produtos utilizados nos tratamentos seguiram as recomendações dos fabricantes. Como tratamento controle foram utilizadas plantas molhadas ou não com água estéril. Uma semana após a aplicação dos respectivos tratamentos e nos tratamentos controle, um disco de $6 \mathrm{~mm}$ de diâmetro de meio de cultura contendo micélio de $S$. sclerotiorum foi colocado na superfície adaxial do primeiro trifólio das plantas, fixando-o com fita adesiva.

As plantas foram mantidas em câmara de crescimento a $22^{\circ} \mathrm{C}$, com fotoperíodo de 12 horas e $80 \%$ de umidade relativa, por 96 horas. Para análise bioquímica, as plantas foram coletadas no momento da inoculação do patógeno, tempo zero, 24, 48, 72 e 96 horas após a inoculação. Para isto, toda a parte aérea foi cortada, embalada em papel alumínio e acondicionada em nitrogênio líquido $\left(-196^{\circ} \mathrm{C}\right)$ Posteriormente, o material vegetal foi armazenado em $-45^{\circ} \mathrm{C}$ até o momento das análises bioquímicas.

As proteínas totais foram quantificadas pelo método descrito por Bradford (6), com soro albumina bovina como padrão. As leituras foram realizadas em espectrofotômetro a $595 \mathrm{~nm}$. A atividade da POX (E.C. 1.11.1.7) foi determinada pelo método de Kar \& Mishra (18), adicionando-se o extrato enzimático e o tampão de reação à cubeta, e as leituras realizadas através do aumento da absorbância (420 nm), com leituras a cada 20 segundos, por um minuto. Para análise da FAL (E.C. 4.3.1.5) foi utilizada metodologia de Hyodo, Kuroda \& Yang (16).

$\mathrm{O}$ experimento foi conduzido em delineamento inteiramente casualizado com cinco repetições por tratamento, realizado em duplicata.

\section{Testes a campo}

Neste estudo, o experimento foi conduzido em uma área agrícola com histórico de incidência do patógeno $S$. sclerotiorum, no município de Coronel Domingos Soares - PR. O clima local é do tipo $\mathrm{Cfb}$ (classificação de Köppen), temperado propriamente dito, com temperatura média no mês mais frio abaixo de $18^{\circ} \mathrm{C}$ (mesotérmico), com verões frescos e temperatura média no mês mais quente abaixo de $22^{\circ} \mathrm{C}$, sem estação seca definida (17).

A semeadura da soja cultivar BMX Ativa foi realizada em sistema 
direto, com 10 sementes por metro e espaçamento de $0,5 \mathrm{~m}$ entre as linhas. As unidades experimentais foram constituídas de parcelas medindo $5 \mathrm{~m}$ de comprimento, contendo cinco linhas, totalizando 12,5 $\mathrm{m}^{2}$. Os tratamentos testados foram os Fosfitos A, B, C e D e água como tratamento testemunha. As aplicações dos tratamentos foram realizadas por meio de um pulverizador costal de pressão constante $\left(\mathrm{CO}_{2}\right)$ e vazão de $150 \mathrm{~L} \mathrm{ha}^{-1}$ nos estádios fenológicos da cultura da soja V4, V4+R1, R1 e R2.

A avaliação da incidência de mofo branco foi realizada no estádio R4, avaliando-se as três linhas centrais de cada parcela, desconsiderando as extremidades $(1 \mathrm{~m})$. As avaliações da severidade foram realizadas nos estádios R5.1 e R5.5. Para isto foram coletadas 30 plantas aleatoriamente, das 3 linhas centrais, e o grau da doença foi determinado por meio da escala de pontos (15): $0=$ planta sem sintoma; 1 = planta com sintoma apenas nos ramos laterais; 2 = planta com sintoma na haste principal, mas sem ocorrência de morte; e 3 = planta morta. O número de plantas mortas foi determinado no estádio R7.

$\mathrm{O}$ experimento foi conduzido em delineamento de blocos ao acaso em esquema fatorial $5 \times 4$ (produtos x épocas de aplicações) com três repetições por tratamento.

\section{Análise estatística}

Todos os dados obtidos nos experimentos foram submetidos a análise de variância ANOVA e quando significativos, as médias foram comparadas pelo teste de Tukey a $5 \%$ de probabilidade de erro.

\section{RESULTADOS}

Testes in vitro e em casa de vegetação

Os fosfitos testados não afetaram o crescimento micelial do fungo S. sclerotiorum em relação ao tratamento testemunha, bem como, não induziram a síntese de gliceolinas em soja, comparando-se os valores obtidos com o controle positivo (dados não apresentados).

Apenas os fosfitos C e D ativaram a síntese da FAL 48 horas após a inoculação do patógeno, em ambos os ensaios (Figura 1 A e B).
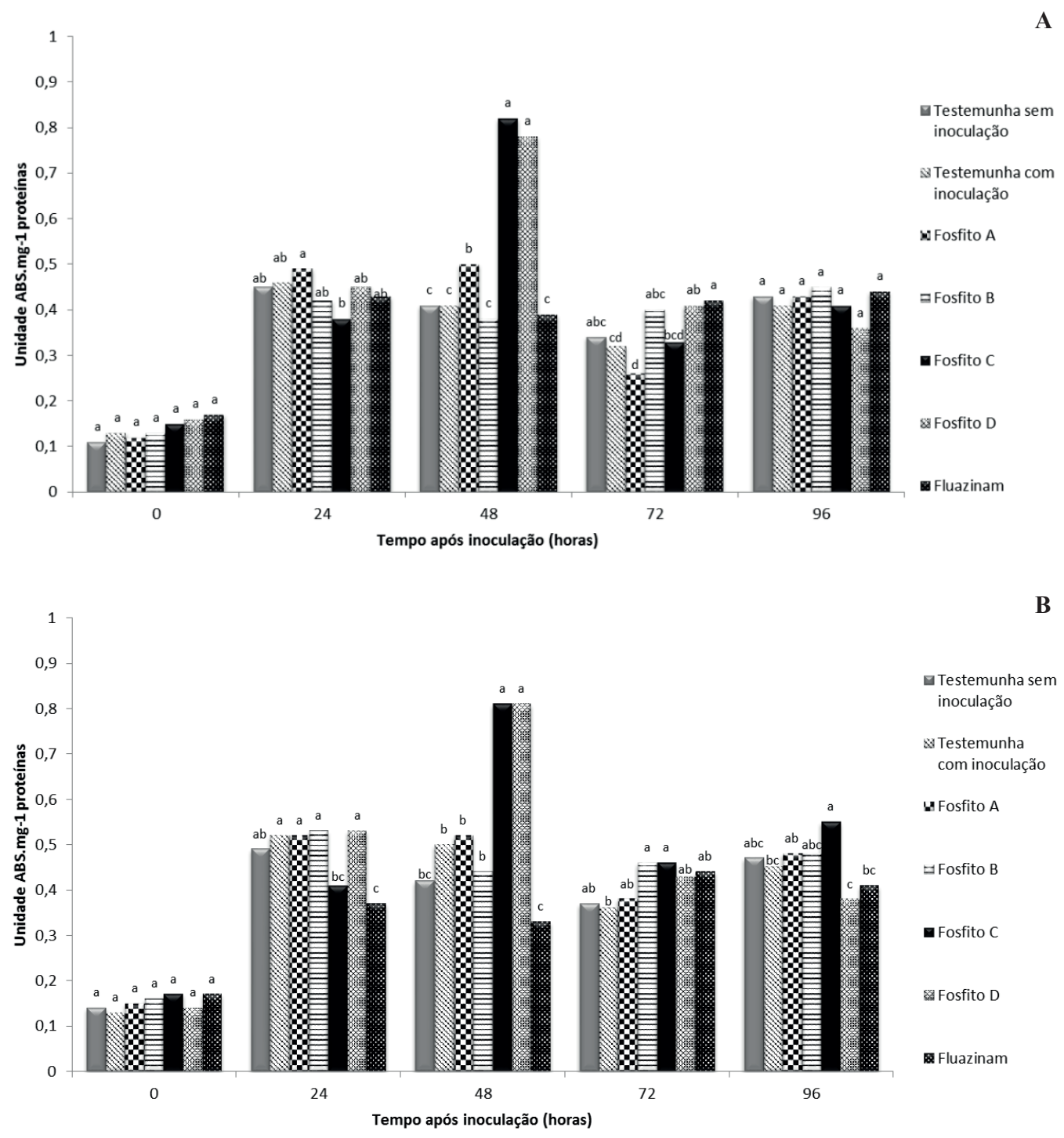

Figura 1. Atividade específica da fenilalanina amônia-liase (FAL) em plantas de soja "BMX Ativa", no estádio vegetativo V2, tratadas com fosfitos de potássio (fosfito A, B, C e D), fungicida fluazinam e inoculadas com o fungo Sclerotinia sclerotiorum, em dois ensaios (A e B). Médias seguidas pela mesma letra não diferem entre si pelo teste de médias de Tukey ao nível de 5\% de probabilidade de erro. 
Em relação a POX houve aumento da atividade desta enzima 24 horas após inoculação com o patógeno, mantendo-se elevada até 96 horas, destacando-se os fosfitos $\mathrm{C}$ e D, em ambos os ensaios (Figura 2 $\mathrm{A}$ e B). $\mathrm{O}$ fosfito $\mathrm{B}$ não ativou a atividade da enzima $\mathrm{POX}$ no período avaliado.

\section{Testes em campo}

Houve interação significativa entre os fosfitos testados e as épocas de aplicação para as variáveis incidência, severidade do mofo branco e número de plantas mortas (Tabelas 1, 2 e 3, respectivamente).

Ao avaliar os fosfitos em cada época de aplicação, os fosfitos $\mathrm{A}, \mathrm{B}$ e $\mathrm{C}$ foram os mais efetivos na redução da incidência do mofo branco em soja quando aplicados em V4. Quando aplicados em $\mathrm{V} 4+\mathrm{R} 1$ apenas o fosfito $\mathrm{B}$ se diferenciou da testemunha, no entanto igualou-se aos fosfitos A e C. A aplicação dos tratamentos nos demais estádios fenológicos não se diferenciaram estatisticamente a $5 \%$ de probabilidade de erro (Tabela 1). Ao analisar a diferença dos tratamentos em cada época de aplicação, destacou-se o fosfito $\mathrm{B}$, quando este foi aplicado em V4+R1, com incidência de 17,2\% (Tabela 1).

Quando avaliou-se a severidade do mofo branco na primeira época de avaliação (R5.1), destacaram-se os fosfitos B e C, quando estes foram aplicados nos estádios fenológicos V4+R1. Quando os tratamentos foram aplicados nos estádios R1 ou R2, os mais efetivos na redução da severidade da doença foram os fosfitos C e D (Tabela 2).

Na segunda época de avaliação da doença (R5.5), os fosfitos A, C e $\mathrm{D}$, quando aplicados no estádio fenológico V4, foram os mais efetivos na redução da severidade da doença. Em V4+R1, destacaram-se os tratamentos com os fosfitos B e C. Quando aplicação dos fosfitos foi
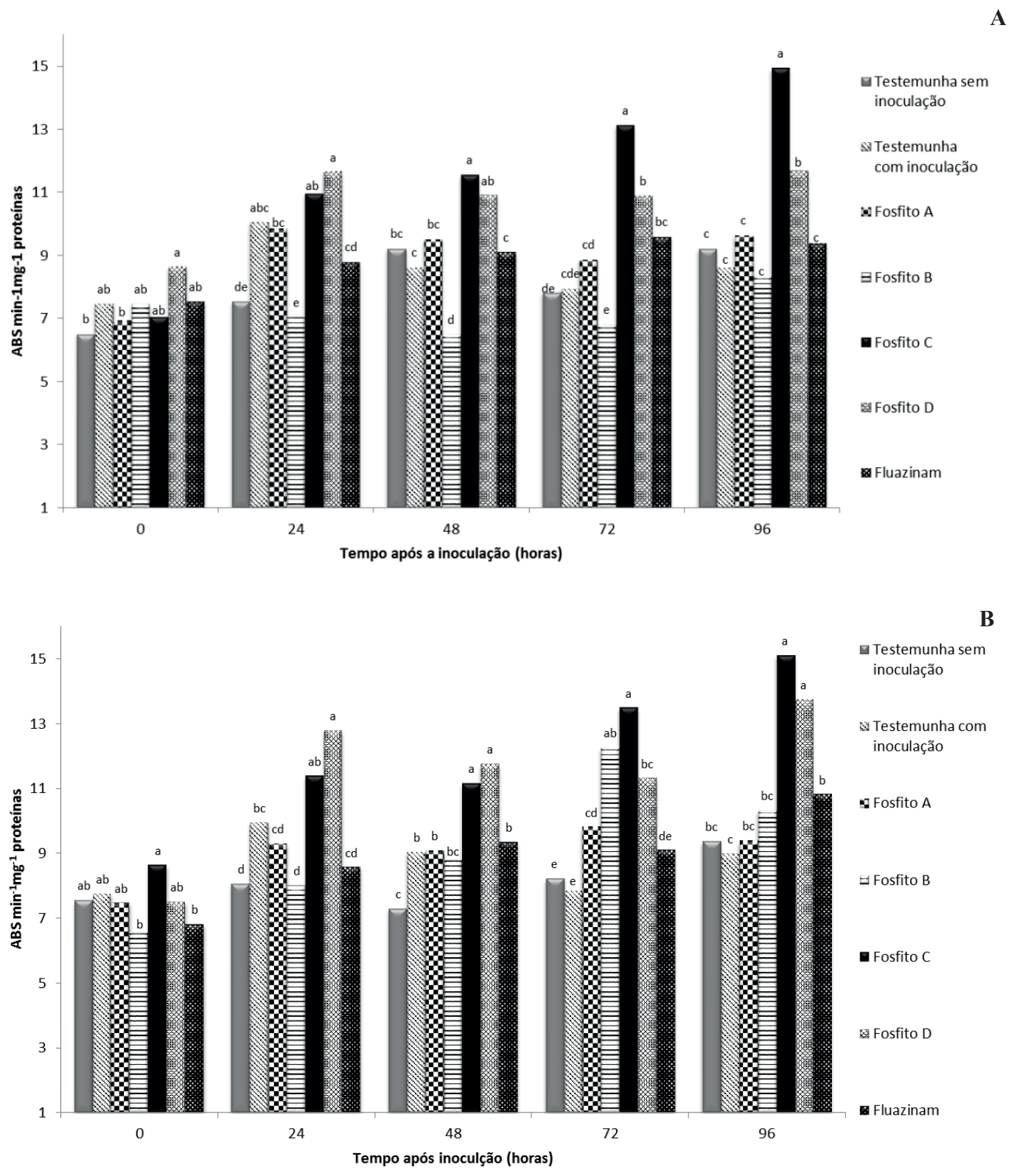

Figura 2. Atividade específica de peroxidase (POX) em plantas de soja "BMX Ativa", no estádio vegetativo V2, tratadas com fosfitos de potássio (fosfito A, B, C e D), fungicida fluazinam e inoculadas com o fungo Sclerotinia sclerotiorum, em dois ensaios (A e B). Médias seguidas pela mesma letra não diferem entre si pelo teste de médias de Tukey ao nível de 5\% de probabilidade de erro. 
Tabela 1. Incidência de mofo branco (\%) em plantas de soja BMX Ativa após a aplicação de diferentes fosfitos em diferentes estados fenológicos.

\begin{tabular}{lcccccccc}
\hline & \multicolumn{7}{c}{ Épocas de aplicação } \\
\hline Produtos & V4 & Controle (\%) & V4+R1 & Controle (\%) & R1 & Controle (\%) & R2 & Controle (\%) \\
\hline Água & $43,3 \mathrm{aA}$ & - & $36,0 \mathrm{aAB}$ & - & $30,4 \mathrm{abB}$ & - & $26,4 \mathrm{aB}$ & - \\
Fosfito A & $20,6 \mathrm{bA}$ & 52 & $28,5 \mathrm{abA}$ & 20 & $32,2 \mathrm{aA}$ & 5 & $29,0 \mathrm{aA}$ & 9 \\
Fosfito B & $25,1 \mathrm{bAB}$ & 42 & $17,2 \mathrm{bB}$ & 52 & $30,0 \mathrm{abA}$ & 1 & $22,2 \mathrm{aAB}$ & 15 \\
Fosfito C & $23,3 \mathrm{bA}$ & 46 & $25,0 \mathrm{abA}$ & 30 & $19,0 \mathrm{bA}$ & 37 & $26,0 \mathrm{aA}$ & 1 \\
Fosfito D & $32,0 \mathrm{abA}$ & 26 & $32,0 \mathrm{aA}$ & 28 & $25,5 \mathrm{abA}$ & 16 & $26,0 \mathrm{aA}$ \\
\hline CV\% & & & & & 19,6 & &
\end{tabular}

*Médias seguidas da mesma letra minúscula na vertical e maiúscula na horizontal, não diferem estatisticamente entre si, ao nível de 5\% pelo teste de médias de Tukey.

Tabela 2. Severidade do mofo branco (\%) em plantas de soja BMX Ativa após a aplicação de diferentes fosfitos em diferentes estados fenológicos e avaliada nos estádios R5.1 e R5.5, da cultivar.

\begin{tabular}{|c|c|c|c|c|c|c|c|c|c|c|c|c|c|c|c|c|}
\hline \multirow{3}{*}{$\begin{array}{l}\text { Produtos } \\
\text { Água }\end{array}$} & \multicolumn{16}{|c|}{ Épocas de aplicação } \\
\hline & \multicolumn{8}{|c|}{ Estádio R5.1 } & \multicolumn{8}{|c|}{ Estádio R5.5 } \\
\hline & \multicolumn{2}{|c|}{ V4 } & \multicolumn{2}{|c|}{ V4+R1 } & \multicolumn{2}{|c|}{ R1 } & \multicolumn{2}{|c|}{$\mathbf{R 2}$} & \multicolumn{2}{|c|}{ V4 } & \multicolumn{2}{|c|}{ V4+R1 } & \multicolumn{2}{|c|}{ R1 } & \multicolumn{2}{|l|}{$\mathbf{R 2}$} \\
\hline Fosfito A & 10,6 & $\mathrm{aA}$ & 12,5 & $\mathrm{aA}$ & 13,6 & $\mathrm{aA}$ & 12,6 & $\mathrm{aA}$ & 11,8 & $\mathrm{bA}$ & 14,3 & $\mathrm{aA}$ & 13,5 & $\mathrm{aA}$ & 15,0 & $\mathrm{bA}$ \\
\hline Fosfito B & 14,0 & $\mathrm{aA}$ & 2,2 & bB & 10,4 & $\mathrm{abA}$ & 13,6 & $\mathrm{aA}$ & 14,7 & $\mathrm{abA}$ & 6,8 & $\mathrm{bB}$ & 11,8 & $\mathrm{abAB}$ & 15,2 & $\mathrm{bA}$ \\
\hline Fosfito D & 12,5 & $\mathrm{aA}$ & 13,6 & $\mathrm{aA}$ & 5,8 & $\mathrm{cB}$ & 5,0 & $\mathrm{bB}$ & 13,5 & $\mathrm{bA}$ & 14,4 & $\mathrm{aA}$ & 7,7 & $\mathrm{bB}$ & 7,7 & $\mathrm{cB}$ \\
\hline $\mathrm{CV} \%$ & & & & & & & & & & & & 17 & & & & \\
\hline
\end{tabular}

*Médias seguidas pela mesma letra minúscula na vertical e maiúscula na horizontal, não diferem estatisticamente entre si, ao nível de $5 \%$ pelo teste de médias de Tukey.

Tabela 3. Número de plantas mortas de soja BMX Ativa após a aplicação de diferentes fosfitos em diferentes estados fenológicos e avaliados no estádio R7.

\begin{tabular}{|c|c|c|c|c|}
\hline \multicolumn{5}{|c|}{ Épocas de aplicação } \\
\hline Água & $14,3 \mathrm{aA}$ & $13,7 \mathrm{aA}$ & $15,0 \mathrm{aA}$ & $14,0 \mathrm{aA}$ \\
\hline Fosfito A & $9,0 \mathrm{bA}$ & $11,7 \mathrm{aA}$ & $9,0 \mathrm{bcA}$ & $11,7 \mathrm{aA}$ \\
\hline Fosfito B & $9,0 \mathrm{bA}$ & $8,7 \mathrm{bcA}$ & $11,7 \mathrm{abA}$ & $11,7 \mathrm{aA}$ \\
\hline Fosfito D & $6,3 \mathrm{bA}$ & $5,0 \mathrm{cA}$ & $6,7 \mathrm{cdA}$ & $7,0 \mathrm{bA}$ \\
\hline $\mathrm{CV} \%$ & & 17,8 & & \\
\hline
\end{tabular}

*Médias seguidas pela mesma letra não diferem entre si pelo teste de médias de Tukey ao nível de 5\% de probabilidade de erro.

nos estádios fenológicos R1 ou R2, sobressaíram-se os tratamentos C e D (Tabela 2).

Todos os fosfitos reduziram o número de plantas mortas quando aplicados em estádio fenológico V4. Quando as aplicações foram em V4+ R1, destacaram-se os fosfitos B, C e D. Em R1, os fosfitos A, C e $\mathrm{D}$ e, em R2 os fosfitos C e D. E, ao analisar a diferença entre as épocas de aplicação para cada fosfito, houve diferença estatística apenas para o fosfito $\mathrm{C}$, onde o menor número de plantas mortas foi observado nos estádios fenológicos R1 e R2 (Tabela 3).

\section{DISCUSSÃO}

Fosfitos de potássio, sobretudo os fosfitos denominados C e D reduziram a intensidade do mofo branco em soja, a campo, principalmente quando foram aplicados nos estádios fenológicos V4+R1, R1 e R2 (Tabelas 2 e 3). O fosfito de potássio pode inibir diretamente a infecção fúngica no tecido hospedeiro ou indiretamente aumentar a resistência a diferentes doenças $(9,1)$. Como nenhum fosfito de potássio testado afetou o crescimento micelial do fungo S. sclerotiorum (dados não apresentados), a indução da resistência 
das plantas promovida pela ativação das enzimas FAL e POX em 48 e a partir de 24 até 96 horas após a inoculação com o patógeno, respectivamente, em casa de vegetação (Figura 2), possivelmente estejam envolvidos no controle desta doença, em condições de campo. Resultado semelhante foi observado em plantas de feijão inoculadas com o fungo Colletotrichum lindemuthianum Sacc. \& Magn. após a aplicação com fosfito de potássio $\left(5 \mathrm{~mL} \mathrm{~L}^{-1}\right)$, neste estudo os autores constataram a ativação da enzima FAL após 8 e 10 dias da aplicação, e da enzima POX após 13 dias da aplicação (24).

Além disso, devido ao aumento da atividade das enzimas POX e PAL, os fosfitos de potássio C e D, podem ter ativado a rota dos fenilpropanóides, sugerindo aumento no teor destes compostos, entre eles a lignina, a qual depende da atividade de peroxidases para sua formação (22) e aumento das proteínas relacionadas à patogênese glucanases e quitinases, que degradam paredes celulares fúngicas. Tais fatos são sugeridos, pois Costa et al. (14) também obtiveram aumentos nos teores de lignina e de compostos fenólicos solúveis, na atividade de POX e superóxido-dismutase, quitinase e glucanase, quando plantas de feijão foram tratadas com fosfitos de $\mathrm{K}$, para o controle da antracnose. A pulverização de plantas de pepino com fosfito de potássio $\left(2 \mathrm{~g} \mathrm{~L}^{-1}\right)$ para o controle de Pseudoperonospora cubensis, induziu o aumento do conteúdo de lignina em $15 \%$ em relação ao tratamento testemunha, e de glucanases e quitinases (23). Tais resultados demonstram que há evidências científicas dos efeitos benéficos dos fosfitos no controle de doenças de plantas em diferentes patossistemas.

Por outro lado, neste estudo, os fosfitos de potássio testados não induziram a produção de gliceolinas nos cotilédones de soja (Figura 1), corroborando os resultados obtidos por Arruda (3), ao avaliar o potencial eliciador de dois fosfitos $\left(30 \% \mathrm{P}_{2} \mathrm{O}_{5}, 20 \% \mathrm{~K}_{2} \mathrm{O}\right.$ e $26 \% \mathrm{P}_{2} \mathrm{O}_{5}$, $19 \% \mathrm{~K}_{2} \mathrm{O}$ ), para controle do mofo branco em soja BMX Ativa. O efeito negativo dos fosfitos de potássio testados no presente estudo na produção de gliceolinas nos cotilédones em soja, possivelmente ocorreu devido às doses empregadas desses produtos que podem não terem sido adequadas para ativação da síntese de gliceolinas, uma vez que, indutores eficientes são ativos em doses muito baixas. Outro fator a ser considerado é o genótipo da planta, que numa interação especifica pode influenciar na quantidade e no tipo de gliceolinas produzidas, e também, a expressão das mesmas pode não ocorrer, dependendo do indutor utilizado $(10,7)$. Além disso, pode ser que os componentes fósforo e potássio presentes nos produtos testados não se ligaram a um receptor especifico na membrana plasmática, ou no interior da célula vegetal e, desta forma, não atuaram na sinalização para produção de gliceolinas, como sugerido por Bertozzi \& Kiessling (5) e Labanca (19). Dessa forma, conclui-se que os fosfitos de potássio testados neste estudo não podem ser considerados eliciadores de gliceolinas em soja, nas condições deste experimento.

Ao serem analisadas as épocas de aplicação sobre a eficiência do controle do mofo branco, para cada produto isolado, observou-se que o fosfito de potássio A apresentou o mesmo comportamento da primeira avaliação. Os fosfitos de potássio $\mathrm{B}$ e $\mathrm{C}$ reduziram a severidade da doença com duas aplicações, quando aplicados em duas épocas (V4+R1) e com uma aplicação apenas, no estádio R1. Já, o fosfito D proporcionou melhor controle da doença com apenas uma aplicação nos estádios R1 ou R2.

Através da análise química expressa no rótulo dos fosfitos de potássio utilizados (Fosfito A: P2O5-40\%; K2O-20\% - 1 L/ha; Fosfito B: P2O5-40\%; K2O-28\% - 1 L/ha); Fosfito C: P2O5-40\%; K2O-20\% - 1 L/ha) e Fosfito D: P2O5-30\%; K2O-20\% - 2,4 L/ha)], sabe-se que os fosfitos $\mathrm{A}$ e $\mathrm{C}$ tem a mesma proporção de fósforo e potássio. Com isso, esperava-se que estes produtos apresentassem o mesmo comportamento no controle do mofo branco (Tabela 3). Tal resultado possivelmente não ocorreu devido aos ingredientes ativos utilizados na composição destes produtos serem de origem diferente e também não se conhece a qualidade de cada um.

Apesar disso, os resultados obtidos neste estudo contribuem para mostrar que os fosfitos proporcionaram uma diminuição da doença em relação ao tratamento testemunha, e podem ser utilizados como um método viável de manejo e ambientalmente correto. Também, podem ser associados a outros métodos para diminuição de perdas ocasionadas por S. sclerotiorum. Eles proporcionaram diminuição da doença, semelhante ou melhor até do que quando são utilizados fungicidas, como nos trabalhos de Arruda (3), que constatou um controle de $16,6 \%$ utilizando o fungicida fluazinam. Meyer et al. (20), utilizando fluazinam, tiofanato metilico e carbendazin, e obtiveram $81,29 \%$ e $19 \%$ de controle de mofo branco, respectivamente.

\section{AGRADECIMENTOS}

Os autores agradem a Coordenação de Aperfeiçoamento de Pessoal de Nível Superior (CAPES) pela concessão de bolsa de estudos ao primeiro e segundo autor.

\section{REFERÊNCIAS}

1. Araujo, L.; Bispo, W. M. S.; Rios, V. S.; Fernandes, S. A.; Rodrigues, F. A. Induction of the phenylpropanoid pathway by acibenzolar-s-methyl and potassium phosphite increases mango resistance to Ceratocystis fimbriata infection. Plant Disease, St. Paul, v. 99, p. 447-459, 2015. DOI: https:// doi.org/10.1094/PDIS-08-14-0788-RE Disponível em: < https://apsjournals apsnet.org/doi/10.1094/PDIS-08-14-0788-RE> Acesso em: 12 out. 2018.

2. Arfaoui, A.; Hadrami, A. E.; Daayf, F. Pre-treatment of soybean plants with calcium stimulates ROS responses and mitigates infection by Sclerotinia sclerotiorum. Plant Physiology and Biochemistry, Bari, v. 122, p. 121-128, 2018. DOI: 10.1016 / j.plaphy.2017.11.014 Disponível em: <https://www. ncbi.nlm.nih.gov/pubmed/29223021> Acesso em: 12 out. 2018.

3. Arruda, J. H. Ação de agroquímicos no controle de mofo branco em soja. 2014. 58 p. Dissertação (Mestrado em Agronomia) - Universidade Tecnológica Federal do Paraná, Pato Branco. Disponível em: http://repositorio. utfpr.edu.br:8080/jspui/bitstream/1/759/1/PB_PPGAG_M_Arruda\%2c\%20 Josicl\%C3\%A9ia\%20H\%C3\%BCffner_2014.pdf. Acesso em: 29 nov. 2018.

4. Ayres, A. R.; Ebel, J.; Finelli, F.; Berger, N.; Albersheim, P. Host-pathogen interactions. IX. Quantitative assays of elicitoractivity and characterization of the elicitor present in the extracellular medium of cultures of Phytophthora megasperma var. sojae. Plant Physiology, Colorado, v. 57, p. 751-759, 1976. DOI: 10.1104/pp.57.5.751 Disponível em: <https://www.ncbi.nlm. nih.gov/pubmed/16659565>. Acesso em: 15 out. 2018.

5. Bertozzi, C. R.; Kiessling, L. L. Chemical glycobiology. Science, Washington, v. 291, p. 2357-2364, 2001.

6. Bradford, M. M. A rapid and sensitive method for the quantification of microgram quantities of protein utilizing the principle of protein-dye binding. Analitycal Biochemistry, Orlando, v. 72, p. 248-254, 1976. DOI: 10.1006 / abio.1976.9999 Disponível em: <https://www.ncbi.nlm.nih.gov/ pubmed/942051> Acesso em: 02 abr 2020.

7. Braga, M. R. Fitoalexinas. In: Pascholati, S. F.; Leite, B.; Stangarlin, J. R.; CIA, P. Interação planta patógeno: fisiologia, bioquímica e biologia molecular. Piracicaba: FEALQ, 2008. p.305-345.

8. Cassetari Neto, D.; Machado, A. Q.; Silva, R. A. Manual de doenças da soja. São Paulo: Cheminova Brasil, 2010. 57 p.

9. Dalio, R. J. D.; Fleischmann, F.; Humez, M.; Osswald, W. Phosphite protects Fagus sylvatica seedlings towards Phytophthora plurivora via local toxicity, priming and facilitation of pathogen recognition. Plos One, Nebraska-Lincoln, v. 9, n. 1, p. 1-10, 2004. DOI: 10.1371/journal.pone.0087860 Disponível em: <https://journals.plos.org/plosone/article?id=10.1371/ journal.pone.0087860>. Acesso em: 26 out. 2018.

10. Daniel, M.; Purkayastha, R. P. Handbook of phytoalexin metabolism and action. New York: Marcel Dekker, 1996. 615 p. 
11. Dianese, A. C.; Blum, L. E. B. uso de fosfitos no manejo de doenças fúngicas em fruteiras e soja. Brasília - DF: Embrapa Cerrados, 2010. (Documentos). Disponível em: https:/www.infoteca.cnptia.embrapa.br/ bitstream/doc/902292/1/doc288.pdf. Acesso em: 29 maio 2018.

12. Dubois, M.; Gilles, K. A.; Hamilton, J. K.; Rebers, P. A.; Smith, F. Colorimetric method for determination of sugars and related substances. Analytical Chemistry, Washington, v. 28, p. 350-356, 1956. DOI: 10.1021/ ac60111a017 Disponível em: <https://pubs.acs.org/doi/abs/10.1021/ ac60111a017.pdf $>$ Acesso em: 29 nov. 2018.

13. Fenn, M. A.; Coffey, M. D. Studies on the in vitro and in vivo antifungal activity of fosethyl-al and phosphorous acid. Phytopathology, St. Paul, v. 74, p. 606-611, 1984. Disponível em: <https://www.fs.fed.us/psw/publications/ fenn/captured/psw_1984_fenn021.pdf.> Acesso em 29 de maio de 2018.

14. Costa, B. H. G.; Resende, M. L. V.; Monteiro, A. C. A.;Ribeiro Junior, P. M.;Botelho, D. M. S.; Silva, B. M. Potassium phosphites in the protection of common bean plants against anthracnose and biochemical defence responses. Journal of Phytopathology, Göttingen, v. 166, n. 2, p. 95-102, 2018. DOI: https://doi.org/10.1111/jph.12665 Disponível em: $<$ https://onlinelibrary.wiley.com/doi/abs/10.1111/jph.12665 > Acesso em: 29 nov. 2018.

15. Grau, C. R.; Radke, V. L. Resistance of soybean cultivars to Sclerotinia sclerotiorum. Plant Disease, St. Paul, v. 66, n. 6, p. 506-508, 1982. DOI: 10.1094 / PD-66-506. Disponível em: < https:/www.apsnet.org/ publications/PlantDisease/BackIssues/Documents/1982Articles/PlantDisease66n06 506.PDF>. Acesso em: 19 nov. 2018.

16. Hyodo, H.; Kuroda, H.; Yang, S. F. Induction of phenylalanine ammonia-lyase and increase in phenolics in lettuce leaves in relation on the development of russet spotting caused by ethylene. Plant Physiology, St. Paul, v. 62, p. 31-35, 1978. DOI: 10.1104/pp.62.1.31 Disponível em: < https:/www. ncbi.nlm.nih.gov/pmc/articles/PMC1092049/> Acesso em 29 nov. 2018.

17. Instituto Agronômico do Paraná. Classificação Climática. Londrina: IAPAR. Disponível em: http://www.iapar.br/modules/conteudo/conteudo.php?conteudo $=863$. Acesso em: 6 set. 2018 .

18. Kar, M.; Mishra, D. Catalase, peroxidase and polyphenoloxodase activities during rice leaf senescence. Plant Physiology, St, Paul, v. 57, p. 315 319, 1976. Disponível em: https://www.ncbi.nlm.nih.gov/pmc/articles/ PMC542015/pdf/plntphys00156-0193.pdf. Acesso em: 29 nov. 2018.

19. Labanca, E. R. G. Purificação parcial de elicitores presentes em Sacharomyces cerevisae: atividade como indutores de resistência em pepino (Cucumis ativus) contra Colletotrichum lagenarium e da sintese de gliceolinas em soja (Glycine max). 2002. 118 p. Dissertação (Mestrado em Agronomia) - Escola Superior de Agricultura Luiz de Queiroz, Universidade de São Paulo, Piracicaba. Disponível em: http://www.teses.usp.br/teses/disponiveis/11/11135/tde-03092002-170446/en.php. Acesso em: 29 nov. 2018.
20. Meyer, M. C.; Nunes Junior, J.; Pimenta, C. B.; Seii, A. H.; Nunes Sobrinho, J. B.; Costa, N. B.; Guarnieri, S. F. Eficiência de fungicidas no controle de mofo branco (Sclerotinia sclerotiorum), em soja, no estado de Goiás. In: Reunião de Pesquisa de Soja da Região Central do Brasil, 32, São Pedro, 2011. Resumos. Londrina: Embrapa Soja, 2011. Disponível em: https:// ainfo.cnptia.embrapa.br/digital/bitstream/item/40595/1/meyerp.148-150. pdf. Acesso em: 29 nov. 2018.

21. Pawlowski, M. L.; Bowen, C. R.; Hill, C. B.; Hartman, G. L. Responses of soybean genotypes to pathogen infection after the application of elicitors. Crop Protection, Nebraska, v. 87, p. 78-84, 2016. DOI: https:// doi.org/10.1016/j.cropro.2016.04.022 Disponível em: < https:/www. sciencedirect.com/science/article/pii/S0261219416300989 >. Acesso em: 22 out. 2018.

22. Punja, Z. K. Genetic engineering of plants to enhance resistance to fungal pathogens. In: Punja, Z. K. Fungal disease in plants: biochemistry molecular biology, and genetic engineering. New York: Food Products, 2004. p. 207-258.

23. Ramezani, M.; Ramezani, F.; Dehestani, A. Exogenous potassium phosphite application improved PR-protein expression and associated physio-biochemical events in cucumber challenged by Pseudoperonospora cubensis. Scientia Horticulturae, Amsterdam, v. 234, p. 335-343, 2018. DOI: 10.1016/j.scienta.2018.02.042. Disponível em: $<$ https://www.sciencedirect. com/science/article/abs/pii/S0304423818301171>Acesso em: 29 nov. 2018.

24. Silva, J. L.; Souza, P. E.; Alves, E.; Pinto, J. E. B. P.; Bertolucci, S. K. V.; Freitas, M. L.O.; Andrade, C. C. L.; Resende, M. L. V. Essential oil of Cymbopogon flexuosus, Vernonia polyanthes and potassium phosphite in control of bean anthracnose. Journal of Medicinal Plants Research, Lagos, v. 9, n. 8, p. 243-253, 2015. DOI: https://doi.org/10.5897/JMPR2014.5718 Disponível em: < https://academicjournals.org/journal/JMPR/article-full-text/BA21EC551307> Acesso em: 26 nov. 2018.

25. Venturoso, L. R.; Bacchi, L. M. A.; Gavassoni, W. L.; Venturoso, L. A. C.; Espindola, D. L. P.; Santos, J. A. E. Produção de soja e germinação carpogênica de Sclerotinia sclerotiorum sob diferentes coberturas de solo. Semina: Ciências Agrárias, Londrina, v. 34, n. 2, p. 615-626, 2013. DOI: 10.5433/1679-0359.2013v34n2p615 Disponível em: < http://www.uel.br/ revistas/uel/index.php/semagrarias/article/view/9697/12565 > Acesso em: 29. nov. 2018.

26. Ziegler, E.; Pontzen, R. Specific inhibition of glucan-elicited glyceolin accumulation in soybeans by extracellular mannan-glycoprotein of Phytophthora megasperma f.sp. glycinea. Physiological Plant Pathology, Berlim, v. 20, p. 321-331, 1982. DOI: https://doi.org/10.1016/00484059(82)90057-1 Disponível em: <https://www.sciencedirect.com/science/ article/abs/pii/0048405982900571> Acesso em: 29 nov. 2018. 